\title{
Communal roosting in a suburban population of Torresian crows (
}

\author{
Susanne E. Everding ${ }^{\mathrm{a}, \mathrm{b}}$, Darryl N. Jones ${ }^{\mathrm{a}, *}$ \\ ${ }^{\text {a Suburban Wildlife Research Group, }}$ \\ Australian School of Environmental Studies, Griffith University, Nathan, Qld. \\ $\underline{4111, \text { Australia }}$ \\ ${ }^{\mathrm{b}}$ Current Address: Department of Biology, Queen's University, Kingston, \\ Ontario, Canada
}

Date: $\quad 26$ August 2004

Word count: $\quad 8221$

*Corresponding author:

Darryl N. Jones

Australian School of Environmental Studies, Griffith University

Nathan, Qld. 4111, Australia

Phone: (07) 3975 7451, Fax: (07) 38757451

Email: D.Jones@griffith.edu.au

Running Head: $\quad$ Everding and Jones: Communal roosting in urban crows

Keywords: $\quad$ Urban ecology; Torresian crows; corvids; urban bird ecology; communal roosts. 


\section{Abstract}

Communal roosting is a well-known phenomenon among numerous species of corvid (Family Corvidae) worldwide. Surprisingly, in Australia this behaviour occurs only in certain urban populations of two species, and is unknown in any of the five native corvid species living away from urban areas. We studied the communal roosting behaviour of Torresian crows (Corvus orru) in the suburbs of Brisbane, Queensland, Australia, by following six radio-tagged birds and by observing in detail the activities of crows as they departed and arrived at focal roosting trees. Several hundred birds were found to use the roosts on most nights, although there was clear seasonal variation; highest numbers were noted during the autumn and lowest were in spring. Radio-tagged adult birds tended to use the same roost regularly, while the juvenile was far less faithful to a particular tree. Roosting behaviour was significantly influenced by cloud cover and temperature and the location of suitable pre-roost gathering sites. We were unable to determine why urban Torresian crows formed large roosting groups but our data did not support the information centre hypothesis.

\section{Introduction}

Communal roosting behaviour in corvids is well-known, having been studied extensively on several continents (Goodwin, 1976; Hansen et al., 2000), during different seasons (Heinrich, 1989; Feare and Mungroo, 1990), and in a wide variety of species (Gyllin et al., 1977; Møller, 1985; Shirota, 1989). The numbers of individuals using these communal roosts vary considerably. While most probably consist of small numbers of birds, some roosting groups of common ravens (Corvus $\underline{\text { corax }}$ ) for example, in both North America (Engel et al., 1992) and Europe (Wright et al., 2003), are known to be as large as 2000 birds. Roosts of rooks (Corvus frugilegus), and jackdaws (Corvus monedula) in the United Kingdom can be made up of tens of thousands of birds (Coombs, 1961), while those of American crows (Corvus brachyrhynchus) in California can reach hundreds of thousands (Gorenzel and Salmon, 1992).

In Australia, despite sustained research on all five corvid species during the 1960s and 1970s (see Rowley, 1967, 1969, 1970, 1973a,b; Rowley and Vestgens, 1973), communal roosting at traditional sites was never recorded (Rowley, 1971). It is worth noting, however, that these studies were confined to rural areas, and much recent work has similarly been undertaken away from the cities (Debus, 1995). Nonetheless, corvids are common in many Australian cities. The urbanization of Australian corvids appears to have occurred mainly during the latter half of the twentieth century, a pattern similar to that observed in many other countries throughout the world (Marzluff et al., 
1 2001). Bell (1980) appears to have been the first worker to draw attention to the increasing abundance of corvids in many urban areas in Australia, although it has not been until relatively recently that detailed studies of any urban corvids have been carried out (Everding, 1995; Stewart, 1997; Everding and Montgomerie, 2000; Sinden, 2002).

Despite the fact that most urban centres in Australia now support significant populations of resident corvids of various species (Bell, 1980; Low, 2002), the formation of large communal roosts is limited to only two species: Torresian crows (Corvus orru) in Brisbane, Queensland, and little ravens (Corvus mellori) in Melbourne, Victoria. This is of particular interest because it appears that this phenomenon may be limited to urban populations of these species, there being no evidence of the formation of large roosts in rural populations (Rowley, 1971; Madge and Burn, 1994).

The colonization of urban areas by corvids throughout the world has typically been accompanied by an increase in human-corvid conflicts, resulting from issues related to fouling and health concerns, perceived impacts on other birds, and the noise associated with roosting activities (Feare and Mungroo, 1990; Jones and Everding, 1993; Soh et al., 2002). In many cities, attempts at management have often been directed at roosts (Shirota, 1989; Gorenzel and Salmon, 1993), though few have proven successful. A significant part of this failure is likely to relate to a poor understanding of the behaviour and ecology of roosting in the particular species (Hansen et al., 2000), a criticism that may be directed at many approaches to the management of urban wildlife problems (Gavin, 1991).

The city of Brisbane, Australia, has a population of more than 1.6 million (1999 data) and is surrounded by the most rapidly expanding urban areas in the country (Australian Bureau of Statistics, 2001). Prior to the 1950s, the Torresian crow was rarely seen in urban areas (Low, 1984) but is now ubiquitous and roosts in large numbers at locations throughout the suburbs (Sinden, 2002). Like corvid populations in other Australian cities (Stewart, 1997; Veerman, 2002), Torresian crow numbers in Brisbane appear to be rising slowly but steadily; Woodall (in press) recently reported a significant increase in reporting rate for the species in garden birds surveys over a twenty year period. In Brisbane and other southern Queensland cities, this has been accompanied by significant increases in the numbers of complaints from residents (Jones and Everding, 1993, 1994), almost all of which relate directly to the noise associated with communal roosts (Jones and Everding, 1993; Sinden and Jones, in press). Although wildlife agencies and public authorities such as city councils are subject to considerable community and political pressure to mitigate this conflict, management options are currently constrained by an almost complete lack of information about the phenomenon of roosting in urban areas, as well as of the urban ecology of the species in general. For example, it is not known whether the same individuals use particular roosting sites 
1 repeatedly, the extent to which roosting group sizes change seasonally, or how ecological or 2 climatic factors may influence roosting behaviour.

In order to address this deficiency, we studied aspects of the behavioural ecology of suburban Torresian crows in Brisbane, Australia, during 1991-94 (Everding, 1995; Jones and Everding, 1993, 1994; Everding and Montgomerie, 2000). Details of movements, habitat use and ecological characteristics of roosting sites have been published elsewhere (Everding and Montgomerie, 2000). Here we describe the daily and seasonal patterns of use at one of the large suburban communal roosting sites areas in the area using data obtained from observations of arrivals and departures of roosting birds and from radiotelemetry of six individuals. The potential functions of communal roosting in urban Torresian crows are also briefly explored.

\section{Study site and methods}

\section{$\underline{2.1 \quad \text { Roost observations }}$}

This study, part of a larger investigation of urban crows in Brisbane (27 $\left.33^{\prime} \mathrm{S}, 153^{\circ} 03^{\prime} \mathrm{E}\right)$ undertaken 1991-1994 (Everding, 1995), focussed on a major communal roosting area used for at least several decades in the Brisbane suburb of Mt. Gravatt, Queensland, Australia. The study site was a 92 ha residential area adjacent to Toohey Forest Park, a large remnant of native forest and woodland (Catterall and Wallace, 1987) entirely surrounded by suburbs. The area lies between 25 and $194 \mathrm{~m}$ above sea level, and the climate is subtropical.

In February 1992, we identified the emergent trees (all tall Eucalyptus sp.) used most regularly by Torresian crows for roosting, and chose six of those for intensive study. These trees were selected because they afforded an unobstructed view of all birds entering and departing the roost. Five of the six roosts were each monitored for five days for each of the four seasons: autumn - 1 March to 13 April 1992; winter - 31 May to 3 July 1992; spring - 2 September to 5 October 1992; and summer - 29 November 1992 to 16 January 1993. The sixth tree was surveyed in autumn and winter only; during spring 1992, this roost was occupied by a pair of nesting Australian magpies (Gymnorhina tibicen), and was abandoned by the crows for both the spring and summer. Within these time periods, the order in which each roost was observed was randomised, and each roost was watched for five consecutive mornings and evenings.

All observations were undertaken by SEE who arrived at the roost at least $70 \mathrm{~min}$ before sunrise for each dawn count and 45 min before sunset for each dusk count. Counting of individual birds entering and departing the roost started with the first bird arriving or departing. The compass 
1 bearing from which every bird had come to the roost, and the direction in which every bird headed when leaving the roost was also recorded. Compass bearings of departing birds were determined by watching each bird until it continued in a straight line; its final departure direction was then assigned to one of eight $45^{\circ}$ directional sectors (N, NE, E etc). Sectors used in analysis refer to the midpoint of the above $45^{\circ}$ intervals. For example, $90^{\circ}$ actually represents the grouping interval spanning $67.5^{\circ}$ to $112.5^{\circ}$. Birds landing in roosts momentarily, and those that departed briefly only to alight again in the same roost, were not included.

Roost departures and arrivals were examined in relation to precise sunrise and sunset times (Queensland Department of Lands, 1993). Sunrise and sunset times are defined here as the times when the upper limb of the sun was on the true horizon. Meteorological information at 0600 and 1800 hours (temperature in degrees $\mathrm{C}$, wind speed in $\mathrm{kph}$, and cloud cover in eighths) was obtained from the Brisbane Bureau of Meteorology from observations recorded at the Brisbane Airport, 14 km from Mt. Gravatt.

\subsection{Radio-tracking}

We radio-tracked six Torresian crows at the study site between April and July 1994 as part of a separate study of crow movements and habitat use (see Everding and Montgomerie, 2000). The data presented here relate to the proportional use of six specific roost trees by the radio-tagged individuals. The birds were fitted with radio-transmitters manufactured by Titley Electronics, Ballina, New South Wales. Transmitter frequencies ranged from 151.279 to $151.880 \mathrm{MHz}$ with the minimum tag frequency separation during radio-tracking being $171 \mathrm{kHz}$, enabling reliable identification of individual birds. The transmitters were attached using a harness of flat clothing elastic, as described by Kenward (1987). A small amount of glue (Loctite ${ }^{\mathrm{TM}}$ ) was placed on the underside of the transmitter to secure it to the birds' back feathers. The transmitter and harness weighed between $15.8 \mathrm{~g}$ and $18.7 \mathrm{~g}$, representing approximately $3.6 \%$ of average body weight.

Crows were captured at a well-used foraging site on the sports ground of the Mt Gravatt campus of Griffith University, using a baited semi-permanent open-topped aviary design adapted from that devised by Rowley (1968) (see Everding, 1995; Everding and Montgomerie, 2000 for further details). During handling, the ages of the captured birds were determined by gape and eye colour (Rowley, 1970). Of the six crows used for telemetry, all but one, a two-year old, were adults.

A 3-element hand-held Yagi antenna and a Regal 2000 (Titley) telemetry receiver were used. All tracking was done either by car or on foot and continued until the transmitter battery failed, typically after about one month. All focal roosts were visited approximately one hour after dark and again before dawn to establish whether or not birds had changed roosts during the night. 


\subsection{Statistical analyses}

To test for intergroup differences between the total number of birds using all roosts per season we used the Kruskal-Wallis test and the nonparametric multiple comparison test for groups with unequal sample sizes (Zar, 1984). These tests were also used to test for seasonal differences between mean departure times from the roost and mean entering times to the roost.

Mean departure and arrival angles were calculated following Zar (1984). The nonparametric Rayleigh test (using data in $45^{\circ}$ segments as per Zar, 1984) was used to determine whether mean directions differed significantly from random. Differences between mean angles used at each roost per season were tested using the chi-squared test described in Batschelet (1981). This is the only nonparametric multi-sample test appropriate for data with a grouping interval greater than $10^{\circ}$ (Batschelet, 1981). For each roost, samples 1, 2, 3 and 4 referred to the columns (c) autumn, winter, spring and summer, respectively. Rows (r) referred to the eight measurement intervals. Thus, there were $(\mathrm{r}-1)(\mathrm{c}-1)$ degrees of freedom, which resulted in 21 degrees of freedom for all roosts except for roost 2, which had 7 degrees of freedom. The total chi-square result for all six roosts is reported.

A runs test was applied to the departing and entering data to determine whether the distributions of birds had random variability. For each roost in each season, the data were pooled for each day of observations using the time of first activity as the starting point. Following Zar (1984), the median of each pooled sample was calculated and we recorded each datum as being either above (+) or below (-) the median. We then tested whether the distributions of runs above and below the median were fewer than would have occurred at random (one-tailed test of contagion) (Zar, 1984). During analysis it was found that the direction of almost all arrivals was overwhelmingly the pre-roost gathering area at Mt. Gravatt, situated immediately to the south of the roosts. Because of this overriding geographical influence on arrivals data, only departure distances are presented.

A partial correlation analysis (Zar, 1984) was used to investigate the possible influence of climatic features on roosting behaviour. Four climatic variables were measured at the start of the main observational session during the morning and evening: temperature $\left({ }^{\circ} \mathrm{C}\right)$ recorded by digital thermometer; windspeed (knots), using a hand-held anenometer; cloud cover (estimated by eye in eighths of sky); and the precise time of sunset and sunrise (determined using data from Queensland Department of Lands, 1993).

\section{Results}

\subsection{Roosting aggregation sizes}


1 The total number of crows using the focal roosts at Mt. Gravatt varied greatly during the year of 2 study (Figs. 1 and 2). Between March 1992 and January 1993, the median total count of crows using the six specific roost trees varied from 227 in autumn, 143 in winter, 101 in summer with the minimum being 48 in spring. The highest count obtained for a single night varied from 378 in autumn to 88 in spring. The differences in total numbers between seasons (calculated as the sum of the total number of birds leaving each of the six roosts at dawn) were significant (Kruskal-Wallis $\underline{\mathrm{H}}$ $=17.286, \underline{\mathrm{N}}=110, \underline{\mathrm{P}}<0.001)$ with the greatest difference occurring between autumn and spring (Nonparametric multiple comparison: $P<0.05$ ). During this period, however, at least six additional trees within a radius of $500 \mathrm{~m}$ of the focal trees were also occupied by roosting crows, one of which numbered at least 100 birds during autumn. Thus, a conservative estimate of the population using the Mt. Gravatt area could be considerably larger than that indicated here. During the study, we estimated that nightly roosting bird numbers in this location were generally 230-350 in autumn and 40-80 in spring.

Roost occupancy among the six main roost trees at Mt. Gravatt was not uniform, with the mean $( \pm \mathrm{SD})$ number of birds using these roosts ranging from $10.8 \pm 5.5$ to $62.5 \pm 28.6$ birds for the year.

\subsection{Roost departures and arrivals}

Crows generally left the roost in the morning during the 50 minutes preceding sunrise (Fig. 1). Typically, early departures involved 5-20 individuals, while later departures were made of 1-5 birds. The mean time at which birds $( \pm$ SD) left roosts at dawn occurred $20.9 \pm 8.9$ min before sunrise, with significant variation between spring and the other three seasons (Fig. 3, $\underline{\mathrm{H}}=76.57, \underline{\mathrm{N}}=4638, \underline{\mathrm{P}}$ < 0.001; Nonparametric multiple comparison-spring vs autumn: $\underline{\mathrm{P}}<0.001$; spring vs winter: $\underline{\mathrm{P}}<$ 0.001; spring vs summer: $\underline{\mathrm{P}}<0.001)$.

Birds usually arrived between $30 \mathrm{~min}$ before and $30 \mathrm{~min}$ after sunset with the mean time of arrival being $11.2 \pm 9.4$ min after sunset (Fig. 2). As with departing birds, there was some variation in the mean arrival times from season to season, with significant differences evident between winter and all other seasons, and between autumn and spring $(\underline{\mathrm{H}}=306.17, \underline{\mathrm{N}}=5393 \underline{\mathrm{P}}<0.001$; Nonparametric multiple comparison-winter vs spring: $\underline{\mathrm{P}}<0.001$; winter vs summer: $\underline{\mathrm{P}}<0.001$; winter vs autumn: $\underline{\mathrm{P}}<0.001$; autumn vs spring: $\underline{\mathrm{P}}<0.001)$.

\section{$\underline{3.3 \text { Climatic influences }}$}


Partial correlation analysis showed that mean arrival times of crows in autumn were significantly correlated with cloud cover and temperature (Table 1). Birds arrived earlier when cloud cover was high and when temperatures were low, and arrived later during low cloud periods and higher temperatures. Temperature was significantly correlated with dawn departure times in winter (Table 1); low temperatures resulted in later departures with birds maximizing time at roosts. Temperature, cloud cover, wind speed and time of sunrise/sunset, were not, however, significantly correlated with the mean departure and arrival times at any other time of year (Table 1).

\subsection{Departure directions}

Crows leaving roosts at dawn generally used angles that differed significantly from random (Table 2). Only during spring were the directions taken by birds leaving any of the roosts (roosts 3 and 4 only; Table 2) statistically indistinguishable from random. In general, on any given morning most birds left the roosts in small groups and followed a similar direction to earlier bird; this predominant direction different markedly between both seasons and individual roosts (Table 2).

In contrast, birds returning to the roost trees immediately prior to settling to roost, did so from the south. This was due primarily to their use of the summit of a nearby prominent hill (Mt. Gravatt) as a pre-roost gathering site, immediately prior to moving toward their roosting trees.

\subsection{Radiotelemetry}

Tagged individuals were tracked for the following periods (number of days tracked; $\mathrm{N}=$ number of times an individual was confirmed to be using a roost): \#871 (28 days; $\mathrm{N}=21$ ); \#381 (46 days; $\mathrm{N}$ = 31); \#880; (32 days; $\mathrm{n}=27$ ); \#279A ( 7 days; $\mathrm{N}=7$ ); \#520 (32 days; $\mathrm{N}=32$ ); and \#279B (32 days; $\mathrm{n}=18$ ). Thus, tagged birds were detected at a roost on more than $80 \%$ (range: $56.3-100.0 \%$ ) of the nights an individual was tracked.

The radiotelemetry data presented here indicates the percentage of fixes an individual bird spent in each of the six focal roost trees (Fig. 3). While each of the birds was detected on most nights of tracking, the percentage of nights each bird used one of the focal roosts varied considerably between individuals, with only \#279A and \#520 being detected on $100 \%$ of possible nights. The detection rates for the other birds (\#880: 84\%; \#871: 75\%; \#381: 67\%; \#279B: 55\%) indicate that these birds spent $45-16 \%$ of tracking nights away from the six focal roosts.

Nonetheless, all birds did use the focal roost trees on a majority of tracking nights, with all but one bird (\#279B) using one particular roost on 76-100\% of nights in which they were detected. Two 
1 birds (\#871 and \#880) did occasionally roost in two or three other focal trees (Fig. 3). Only one bird

(\#279B), however, appeared to move repeatedly between roost sites through the period of tracking. This individual, notably the only non-adult among the sample, was the only bird to have roosted in all six of the focal roosts during the 32 days of tracking. Moreover, this bird roosted away from the Mt. Gravatt trees during almost half of these days.

Of the 136 tracking fixes obtained at night, 116 (85\%) were from roosts used consistently by the birds (Figure 3). Crows \#871 and \#279B, \#871 and \#381, and \#520 and \#279B used the same roost for some nights, but only birds \#279B and \#520 shared the same main roost (44\% of the total fixes found for \#279B were at the same roost where \#520 spent $100 \%$ of its roosting nights). Half of the birds that were followed used only one roost for the entire tracking period. Thus, all of the tagged birds remained faithful to a single roost for most the period over which they were tracked.

\section{Discussion}

\subsection{Roosting aggregation sizes}

The aggregation of several hundred Torresian crows roosting during most of the year at Mt. Gravatt is large by Australian standards, and is only one of at least nine such roosting locations found throughout the suburbs of Brisbane (Sinden, 2002). No other city in Australia is known to support such large permanent concentrations of roosting corvids (Stewart, 1997; Veerman, 2002), although we have received reliable unpublished data of roosts of little ravens from Melbourne numbering '30+', '40+' and 'over 100' (R. Loyn, pers.comm., I. Temby, pers.comm., P. Veerman, pers.comm.). Although Australian ravens ( Canberra and Perth, roosting groups rarely exceed 6-8 (G. Turner, pers. comm.; Veerman, 2002). In rural areas, Rowley (1973a) reported that Australian ravens did not roost in traditional sites although occasionally groups of about 30 birds were detected in trees adjacent to the current food supply. These groups consisted mainly of immatures and non-breeding adults and tended to occur after the breeding season. In the present study, the conspicuous peak in numbers in autumn almost certainly reflects the use of roosts by both adults and younger birds that had not dispersed, a demographic characteristic of many corvids (Goodwin, 1976; Ratcliffe, 1997). The decline in numbers during the spring possibly indicates that breeding adults were remaining on territories close to the nest, and were not roosting communally. A 
This pattern of seasonal dispersal is similar to that of other Australian corvids (Rowley, 1973a). Young Australian ravens leave their territories to join flocks of conspecifics in late summer, and remain in the local area through autumn and winter, provided food is locally abundant. When food is scarce, these birds disperse to other areas. Little is known about the other territorial Australian species, but Rowley (1973a) suggested a similar pattern for rural Torresian crows and forest ravens (Corvus tasmanicus). The little raven and little crow (Corvus bennetti) tend to leave the nest territory sooner than the other species; both are nomadic and may travel hundreds of kilometres from their natal areas (Rowley, 1973a). Peak numbers of roosting common ravens in Oregon, U.S.A, also coincided with the post-fledgling period (Engel et al., 1992).

The differential use of particular trees within the general roosting area at Mt. Gravatt (Figs. 3) indicated that some trees may have been preferred more than others. Characteristics of the trees used for roosting will be discussed in detail in a separate paper but in general, the trees supporting the largest numbers of roosting birds were typically the tallest eucalypt with the largest canopy. Variation in the number of birds using certain trees might also suggest that some roosts had reached their carrying capacity, although this is unlikely. The differences in the numbers of birds using particular trees in autumn compared to the numbers using roosts over the other seasons, clearly indicated that the trees were capable of holding more birds than they often do.

Roosting sites (as opposed to particular trees within such sites) preferred by urban Torresian crows may be closer to important geographic features such as suitable pre-roost gathering areas (Everding 1995). The northern edge of the nearby (less than $500 \mathrm{~m}$ ) forested hillside within Toohey Forest Park was used on most days as a staging area for crows gathering prior to using the Mt. Gravatt roost trees. Similarly, all of the other major roosting areas within Brisbane (those attracting more than 50-100 birds) are centred on conspicuous groups of large eucalypt trees growing within suburban areas immediately adjacent to forested hills (D. Jones, unpublished data). Similarly habitat-based pre-roost staging areas are common in many avian species (Ward and Zahavi, 1973), and have been documented in other corvids (Stouffer and Caccamise, 1991; Hansen et al., 2000). In the U.K., for example, Coombs (1961) found rooks, jackdaws, common ravens and carrion crows (Corvus corone) using specific fields and hedgerows as pre-roost assembly points. In Oregon, U.S., common ravens often used dry lake beds or conspicuous areas of short vegetation close to their roosts in a similar manner (Engel et al., 1992). In Australia, urban little ravens gathered on the buildings of a large shopping centre complex prior to roosting (I. Temby, pers. comm.). Clearly, corvid pre-roost assembly sites are not limited to particular types of habitat though all tend to be conspicuous and to provide a clear view of the surrounding area (Ward and Zahavi, 1973; Hansen et al., 2000). 


\subsection{Departure and arrival times and climatic influences on roosting}

In many communal roosting species, roosting departure and arrival times are significantly influenced by environmental factors. Haase (1963) found that leaving and entering times among roosting American crows were affected by varying light intensities. Rooks respond to relatively low light intensities by leaving their primary assembly points earlier than on days of high light intensity (Swingland, 1976). Initial departure towards the roost from feeding areas in European starlings (Sturnus vulgaris) was also closely correlated with light intensity, although actual arrival at the roost was not (Davis and Lussenhop, 1970).

In every season, Torresian crows consistently departed roosts almost an hour before sunrise, and returned to roosts after sunset (Figs. 1,2). While there was some variation in mean departure and arrival times between seasons, the maximum time differences were small. It is unlikely then, given the uniformity of mean departure and arrival times, that the variation observed had significant biological significance. These movements did, however, correlate with cloud cover and temperature at dusk during autumn, and with temperature only at dawn during winter (Table 1). Since autumn was generally cloudier than any other season, it is perhaps not surprising that the birds responded to the cloud increase by spending more time at the roost. Cloud cover is often indicative of impending inclement weather, a time when birds may benefit energetically by remaining longer in sheltered areas.

The correlation between temperature and the increased time spent at roosts is somewhat surprising (Table 1). That temperature influences the roosting times of birds in temperate climates is well known (Reebs, 1986; Brodsky and Weatherhead, 1984). However, we did not expect that a relatively large crow (mean mass: $511 \pm 44.2 \mathrm{~g}, \mathrm{n}=46$, this study) living in a subtropical climate, would be affected by relatively small variations in seasonal temperatures. The maximum mean temperature in the peak of summer in Brisbane was $29.2^{\circ} \mathrm{C}$, while the minimum mean temperature in winter was $8.8^{\circ} \mathrm{C}$, a difference of $20.4^{\circ}$. In contrast, relatively small $(14.5 \mathrm{~g})$ American goldfinches (Carduelis tristis), wintering in temperate Michigan, U.S.A., endure 15-hour roost periods at overnight temperatures as low as $-40^{\circ} \mathrm{C}$ (Buttemer, 1985). Nonetheless, it is likely that crows do receive some energetic benefits by maximizing their time at the roost during colder temperatures; although such considerations may more importantly influence small birds using winter roosts, all birds will derive some energy savings by using and remaining at roost sites that restrict convective and radiative heat to the environment (Buttemer, 1985). 


\subsection{Departure and arrival directions}

Our data indicate that crows using the six focal roost trees departed from and arrived at roosts from directions that differed significantly from random. The angles of departing birds may suggest that birds used many areas adjacent to the roosts because food supplies were evenly distributed in patches of equal or near-equal quality. If birds had left from the roosting area in one or a few directions, we would have expected that food was concentrated in these directions.

Birds entering the roosts at dusk generally arrived from a southerly direction, from Mt. Gravatt, a nearby prominent hill of 194 m elevation, within Toohey Forest Park. Our observations indicated that most birds joined others in flight over the forest before settling into individual roost trees growing close together about $300 \mathrm{~m}$ below the hilltop and immediately outside the boundary of the forest. Evening roosting was always preceded by these gatherings of many birds over the forest, with the growing flock making numerous highly conspicuous flights over the site prior to roosting. It is very likely that these flights, made near a prominent geographical feature, would have been used by other crows seeking to join the roosting birds, especially late in the evening.

\section{$\underline{4.4 \text { Roost tenure by radio-tagged individuals }}$}

Assuming that the birds captured for radiotelemetry were representative of crows roosting at the Mt Gravatt site generally, our data suggest that adults tended to use the same trees within the roost: each of the adults used the same tree either every night (three of the five tagged adults) or on almost $80 \%$ (Fig. 3) of nights for the remaining two individuals. Notably, both of the latter birds (\#871 and \#880) were tracked during late autumn and early winter, periods when roost occupancy was at its highest. One interpretation of the fact that both of these birds temporarily used other roost trees may be due to competition for space in their favoured tree (Sonerud et al., 2002). Normally, however, all birds appeared to favour a particular tree where possible.

Obviously, such a conclusion relates only to adults and only to birds not involved in breeding activities. The roosting behaviour of the only non-adult among the sample (\#279B) was distinctly different to that of the adults. This presumably unpaired two-year-old individual (sex was unknown), was the only one to use all trees in the Mt Gravatt site as well as to spend significant periods elsewhere. It is well known that younger, unpaired corvids are by far the most mobile birds within their populations (Goodwin, 1976; Hansen et al. 2000; Marzluff et al. 2001), and the relatively unpredictable movements of such birds are the primary reasons for the fluctuations in the 
1 numbers of birds occupying roosts, at both a daily and seasonal scale. Our data support this general observation for Torresian crows in an urban setting.

\subsection{Why do urban Torresian crows form communal roosts?}

Although communal roosting is a well-known feature of many corvids worldwide, the present study is the first to describe the phenomenon in an Australian species. What is noteworthy here is not the fact that communal roosting occurs in the study species, but that it appears to be limited to urban populations. Similar roosting behaviour appears also to occur in urban-dwelling little ravens (I. Temby, pers. comm.), and although little information is available for that species, it is very likely that similar ecological influences as those affecting the Torresian crow are in operation. Only one of the other Australian corvids, the Australian raven, is abundant in large cities and nowhere is it known to roost in significant numbers (Rowley, 1973a; Stewart, 1997; Veerman, 2002; G. Turner, pers. comm.). Unlike the Torresian crow and little raven, the Australian raven is also less likely to form large flocks, even in the vicinity of rich foraging resources (Rowley, 1973a; Madge and Burn, 1999).

Communal roosting itself has been the subject of considerable theoretical and empirical interest, especially since Ward and Zahavi (1973) proposed their 'information centre hypothesis' (see also Mock et al., 1988; Marzluff et al., 1996). While numerous studies on a variety of species have both supported and rejected this particular hypothesis, the widespread interest in attempting to understand communal roosting has generated a variety of related hypotheses, most of which attempt to explain the adaptive influences leading birds to aggregate each night (Mock et al., 1988; Hansen et al. 2000).

An evaluation of these hypotheses is well beyond the scope of the present study. Some of our findings are, however, of relevance to continuing attempts at understanding the phenomenon. For example, proponents of the information centre hypothesis argue that the adaptive significance of communal roosting in birds involves an exchange of information between roost members about the location of good feeding areas (Rabenold, 1987; Marzluff et al., 1996). Unsuccessful foragers may gain such information from successful foragers at the roost, and subsequently follow them to their feeding areas. One of the requirements of this hypothesis is that less-successful birds should follow knowledgeable roost members from the roost (Mock et al., 1988; Marzluff et al., 1996), behaviour that should be evident in the relatively tight synchrony among birds leaving the roost.

There are several reasons why this mechanism of information exchange did not appear to operate among the Torresian crows studied here. First, although a majority of departing birds did leave in a 
1 distinct peak prior to sunrise (Fig. 1), the rate of departure was almost identical for all seasons, and 2 it took between $47 \mathrm{~min}$ and $90 \mathrm{~min}$ for all birds to leave the roost. Moreover, there were no differences in the rates of arrivals compared to departures for seasons; temporally clumped departures, but not arrivals, are predicted by the information centre hypothesis (Mock et al., 1988).

Second, the distribution and types of food utilised by Torresian crows in Brisbane are unlikely to be conducive to the maintenance of information centres. The species is known to eat a wide variety of foods in rural Australia, with ground-dwelling invertebrates predominating in the diet (Rowley and Vestjens, 1973). In the suburbs, their already catholic diet is substantially supplemented with carrion and many different anthropogenic foods, almost all of which are obtained while foraging on the ground (Sinden, 2002). The subtropical environment in Brisbane, along with its well-watered lawns and sports fields, almost certainly ensures that crows are provided with a relatively dependable source of invertebrate fauna (Sinden, 2002). Recent studies on the foraging ecology of Australian magpies (Gymnorhina tibicen), a species with a similar foraging ecology to the Torresian crow (Brown and Veltman, 1987), in Brisbane (Rollinson, 2003), confirm that, apart from prolonged periods of dry weather (O'Leary and Jones, 2002), ground-derived invertebrates were relatively abundant throughout the year in urban areas. In rural areas nearby, however, these prey were far more patchily distributed and were particularly rare during drier periods (Rollinson, 2003). In the urban environment, crows are unlikely to have difficulties finding food on most days, and therefore would not be dependant upon receiving information about the location of good feeding areas from other birds. In addition, food bonanzas such as large mammal carcasses, which last several days, do not occur regularly in suburban Brisbane. The ecological context of the information centre hypothesis is normally one is which the food supply is unpredictable, irregularly distributed, and available for a sufficient period to enable the participation of newly recruited birds (Marzluff et al., 1996).

Unsuccessful foragers use information centres to improve their own foraging efficiency, and the information about superior feeding areas is given in some form at the roost (Ward and Zahavi, 1973). This type of information transfer contrasts with 'local enhancement' (Thorpe, 1963), whereby individuals cue in on other foraging individuals to find food. In the present study, we found that radio-tracked Torresian crows did not travel far from the roost (mean distance travelled per day $=3.7 \mathrm{~km}$; Everding, 1995). Thus, it is likely that the feeding flocks of crows observed in the study area probably formed through the attraction of conspecifics to feeding individuals.

A variant of local enhancement termed 'network foraging', describes group foraging as a loose, sparse collection of naive individuals dispersing within visual contact (Wittenberger and Hunt, 1985). All such birds search for food independently, and when one bird discovers food, the 
1 members of the flock follow, until a congregation of feeding birds is formed. Based on information

2 obtained from radio-tracking individual birds (Everding and Montgomerie, 2000) and observations 3 of foraging groups (Sinden, 2002), Torresian crows do not regularly forage in large, tightly-knit feeding flocks in Brisbane, although they may participate in a loose 'network'. We often observed that when food had been depleted in locations where birds had fed in large numbers, these assemblages quickly dispersed, presumably to resume their independent foraging (see Everding, 1995).

Another adaptive explanation of the evolution of communal roosting relates to the enhancement of individual survival through a variety of behavioural mechanisms including improved vigilance for predators (see Pulliam and Caraco, 1984). In the present study we found no signs of predation on Torresian crows at or near roosts, even though large numbers of these conspicuous birds returned regularly to the same trees. Non-nesting corvids in many countries including Australia (Rowley, 1973a; Kelly and Thorpe, 1993) appear to have few obvious predators except for humans. Given the apparently low predation rate on Torresian crows, it is unlikely that the fundamental importance of communal roosting is protection against predation.

Another explanation for communal roosting is that roosts form as passive aggregations near abundant food supplies (Caccamise and Morrison, 1986). Thus, communally roosting birds are thought to visit centrally located 'diurnal activity centres', during the day for feeding, and may roost near a superabundant feeding area located outside of the diurnal activity centres. One prediction of this 'patch-sitting hypothesis' is that birds should be more faithful to their diurnal activity centres

than their roosts (Caccamise and Morrison, 1986). Radio-tracked Torresian crows, however, exhibited much stronger roost fidelity than fidelity to a foraging area, although birds did visit some parts of their home range regularly (Everding and Montgomerie, 2000).

We suggest that both local enhancement and network foraging strategies may operate in this study population: crows travelled from roosts singly, in pairs, and small groups to many predictable foraging areas, and occasionally benefited from social foraging if it resulted in a more efficient search of the local area. However, distinguishing between the numerous competing functional explanations remains a significant challenge (Hansen et al., 2000). Discerning the function(s) of communal roosts of urban Torresian crow roosts must remain largely speculative in the absence of more detailed comparisons of, in particular, roost-associated movements and food resource distribution between urban populations and non-urban populations where communal roosting does not occur.

\section{$\underline{4.5 \text { Implication for management }}$}


Although it is far from clear why urban populations of Torresian crows form large communal roosts, their presence within urban areas is the source of a significant and growing conflict (Jones and Everding, 1994). By far the most important aspect of this conflict relates to the noise produced by roosting birds (Sinden, 2002); a significant proportion of people living within 200-400 m of the roosting trees regarded this noise as sufficiently important to require some form of management action, although there was very little support for culling or the removal of roosting trees (Jones and Everding, 1993,1994; Everding, 1995). As elsewhere, the most obvious approach to the mitigation of a roost-based conflict would appear to be a reduction in the number of birds using a particular roost (Gorenzel and Salmon, 1993).

Our findings suggest that while adult crows do prefer to spend the night in the same tree, younger birds are much more likely to move among different trees. Evidence from numerous studies (Engel et al., 1992; Hansen et al., 2000) indicates that the majority of birds using a communal roost are younger, unpaired birds, who exhibit low fidelity to a particular roosting site. It is the movement of these birds among the roosting sites, and between the individual trees within, that accounts for the often large daily and seasonal variation in numbers. While the reasons leading to the particular aggregation of birds in a specific tree may be complex (including competition for space, dominance influences, climatic factors; Sonerud et al., 2002), it appears that disturbances at the time of settling in the evening are especially pertinent for birds in the process of deciding where to spend the night (Gorenzel and Salmon, 1993, 1995). A variety of techniques have been devised to take advantage of this pre-roosting flightiness, including the use of balloons, kites and, most effectively, taped distress calls (Shirota, 1989; Gorenzel and Salmon, 1993). Only the first of these has been used on Torresian crows with definite though temporary success; while virtually all birds vacated the roost on the night of the experimental disturbance, numbers had returned to normal within a week (D. Jones, unpublished data). We suspect that this was due to the arrival of substantial numbers of new birds, most probably mobile young birds, as well as the return of older birds that used the tree as their traditional 'home' roost. Similar results were obtained in an attempt to disperse American crows from roosts using lasers (Gorenzel et al., 2002): although immediate reactions were impressive, with all birds leaving the trees, many returned quickly and no roosts were abandoned.

Although the roosting aggregations of Torresian crows described here are relatively small compared to those found in numerous Northern Hemisphere cities ( $\mathrm{xxx}$ ), the nature of the conflicts associated with these groups are no less challenging for managers. The increasing number of large roosts within the suburban areas of Brisbane, and the attendant calls for control (Sinden and Jones, in press; Jones and Everding, 1994), may necessitate innovative management approaches. The 
1 apparent preference of Torresian crows for roosting in large eucalypt trees with a complete canopy

2 (Everding, 1995) suggests that manipulation of tree structure through the strategic removal of certain branches may be worthy of assessment.

\section{Acknowledgements}

We are extremely grateful to the following people: Lori Monro, Kate Park and especially Steve Gammon, for invaluable assistance in the field; Robert Montgomerie for much advice on analyses; and Ric Nattrass from the Queensland Parks and Wildlife Service, for his intimate knowledge of Brisbane's urban wildlife. Chris Davey, Richard Loyn, Ian Temby, Graham Turner, and Philip Veerman kindly shared their unpublished observations on Australian corvids; Ian Temby and Philip Veerman also offered valuable suggestions on an earlier draft. This research was undertaken with the financial support of a Griffith University Postgraduate Research Scholarship, and the approval of the Griffith University Committee for Experimentation on Animals (Permit number aes/03/90/aec), Queensland Parks and Wildlife Service and the Australian Bird and Bat Banding Scheme.

\section{References}

Australian Bureau of Statistics., 2001. Australia now: Population distribution. http://www.abs.gov.au/ausstats/ABS\%40.nsf (accessed August 6, 2002).

Batschelet, E., 1981. Circular Statistics in Biology. Academic Press, New York.

Bell, H., 1980. The house crow is coming. Wingspan 5, 20.

Buttemer, W.A., 1985. Energy relations of winter roost-site utilisation by American goldfinches (Carduelis tristis). Oecologia 68, 126-132.

Brodsky, L.M., Weatherhead, P.J., 1984. Behavioural thermoregulation in wintering black ducks: roosting and resting. Can. J. Zool. 62, 1223-1226.

Brown, E.D., Veltman, C.J. 1987. Ethogram of the Australian magpie (Gymnorhina tibicen) in comparison to other Cracticidae and Corvus species. Ethology 76, 309-333.

Caccamise, D.F., Morrison, D.W., 1986. Avian communal roosting: implications of diurnal activity centres. Am. Nat. 128, 191-198.

Catterall, C.P., Wallace, C.J. 1987. An Island in Suburbia. Institute of Applied Environmental Research, Griffith University, Brisbane. 
1 Coombs, C.J.F., 1961. Rookeries and roosts of the rook and jackdaw in south-west Cornwall. Bird Study 8, 55-70.

Davis, G.J., Lussenhop, J.F., 1970. Roosting of starlings (Sturnus vulgaris): a function of light and time. Anim. Behav. 18, 362-365.

Debus, S., 1995. Crows and ravens. Wingspan 5(4), 38-42.

Engel K.A., Young, L.S., Steenhof, K., Roppe, J.A., Kochert, M.N. 1992. Communal roosting Common Ravens in southwestern Idaho. Wilson Bull. 104, 105-121.

Everding, S.E., 1995. Movements and habitat use of the Torresian Crow in a Suburban Environment. M.Sc. thesis, Griffith University, Brisbane.

Everding, S.E., Montgomerie, R., 2000. Movements and habitat use of the Torresian crow in a subtropical suburban environment. Emu 100, 192-198.

Feare, C.J., Mungroo, Y., 1990. The status and management of the House Crow Corvus splendens (Viellot) in Mauritius. Biol. Cons. 51, 63-70.

Gavin, T.A., 1991. Why ask "why": the importance of evolutionary biology in wildlife science. J. Wildl. Manag. 55, 760-766.

Goodwin, D., 1976. Crows of the World. University of Queensland Press, Brisbane.

Gorenzel, W.P., Blackwell, B.F., Simmons, T.P, Dolbeer, R.A., 2002. Evaluation of lasers to disperse American crows, Corvus brachyrhynchus, from urban night roosts. Int. J. Pest. Manage. 48, 327-331.

Gorenzel, W.P., Salmon, T.P., 1992. Urban crow roosts in California. Proc. Vert. Pest. Conf. 15, 97-102.

Gorenzel, W.P., Salmon, T.P., 1993. Tape-recorded calls disperse American crows from urban roosts. Wildl. Soc. Bull. 21, 334-338.

Gorenzel, W.P., Salmon, T.P., 1995. Characteristics of American crow urban roosts in California. J. Wildl. Manage. 59, 638-645.

Gyllin, R., Källander, H., Sylvén., 1977. The microclimate explanation of town centre roosts of jackdaws Corvus monedula. Ibis 119, 358-361.

Haase, B.L., 1963. The winter flocking behaviour of the common crow (Corvus brachyrhynchus Brehm.) Ohio J. Zool. 63, 145-151.

Hansen, H., Smedshaug, C.A., Sonerud G.A., 2000. Preroosting behaviour of hooded crows (Corvus corone cornix). Can. J. Zool. 78, 1813-1821.

Heinrich, B. (1989) Ravens in Winter. Summit Books, New York.

Jones, D.N., Everding, S.E., 1993. Crows in suburbia. Cumberland Bird Observers Club Newsletter $14,1-3$. 
Jones, D.N., Everding, S.E., 1994. Torresian crows: Urban terrorists or useful opportunists. Wildlife Australia 31(4), 4-7.

Kelly, G.M., Thorpe, J.P., 1993. A communal roost of peregrine falcons and other raptors. Brit. Birds 86, 49-52.

Kenward, R.E. 1987. Wildlife Radio Tagging: Equipment, Field Techniques and Data Analysis. Academic Press, London.

Low. T., 2002. The New Nature. Penguin, Sydney.

Madge, S., Burn, H., 1994. Crows and Jays: A Guide to the Crows, Jays and Magpies of the World. Christopher Helm, London.

Marzluff, J.M., Heinrich B., Marzluff, C.S., 1996. Raven roosts are mobile information centres. Anim. Behav. 51, 89-103.

Marzluff, J.M., McGowan, K.J., Donnelly, R., Knight, R.L. 2001. Causes and consequences of expanding American crow populations. In: Marzluff, J.M., Bowman, R., R. Donnelly (Eds.). Avian Ecology and Conservation in an Urbanizing World. Kluwer Academic, Norwell, MA., pp 331-363.

Mock, D.W., Lamey, T.C., Thompson, D.B.A., 1988. Falsifiability and the information centre hypothesis. Ornis Scand. 19, 231-248.

Moller, A.P. 1985. Communal roosting in the magpie (Pica pica) .J. Ornithol. 126, 405-419.

O'Leary, R.A., Jones, D.N. 2002. Foraging by suburban Australian magpies during dry conditions. Corella 26, 53-54.

Pulliam, H.R., Caraco, T., 1984. Living in groups: Is there an optimal size? In: Krebs, J.R., Davies, N.B. (Eds.). Behavioural Ecology: An Evolutionary Perspective. Blackwell, Oxford, pp 122-147.

Queensland Department of Lands., 1993. Brisbane and Environs Non-Leap Year Sunrise/Sunset Tables. Queensland Department of Lands, Brisbane.

Rabenold, P.P., 1987. Recruitment to food in black vultures: evidence for following from communal roosts. Anim. Behav. 35, 1775-1785.

Ratcliffe, D., 1997. The Raven: A Natural History in Britain and Ireland. Academic Press, London.

Reebs, S.G., 1986. Influence of temperature and other factors on the daily roosting times of blackbilled magpies. Can. J. Zool. 64, 1614-1619.

Rollinson, D., 2003. Foraging ecology of rural and suburban Australian magpies (Gymnorhina tibicen). Ph.D. thesis, Griffith University, Brisbane.

Rowley, I., 1967. A fourth species of Australian corvid. Emu 66: 190-210.

Rowley, I. 1968. The ABC of crow catching. Aust. Bird Bander 15, 47-55. 
1 Rowley, I., 1969. An evaluation of predation by 'crows' on young lambs. C.S.I.R.O Wildlife Research 14, 153-179.

Rowley, I., 1970. The genus Corvus in Australia. C.S.I.R.O Wildlife Research 15, 27-71.

Rowley, I., 1971. Movements and longevity of ravens in south-eastern Australia. C.S.I.R.O Wildlife Research 16, 49-72.

Rowley, I., 1973a. The comparative ecology of Australian corvids. II. Social organization and behaviour. C.S.I.R.O Wildlife Research 18, 25-65.

Rowley, I., 1973b. The comparative ecology of Australian corvids. VI. Why five species? C.S.I.R.O Wildlife Research 18, 157-169.

Rowley, I., Vestgens, W.J.M., 1973. The comparative ecology of Australian corvids. V. Food. C.S.I.R.O Wildlife Research 18, 131-155.

Shirota, Y., 1989. A new method to scare crows Corvus macrorynchus and C. corone. Bird Behav. $8,1-7$.

Sinden, K., 2002. Synanthropy of the Torresian crow in the Greater Brisbane Region: Abundance, foraging and conflicts. BSc Honours Thesis, Griffith University, Brisbane.

Sinden, K.E., Jones, D.N., (in press). Living with crows. Nature Australia.

Soh, M.C.K., Sodhi, N.S., Seoh, R.K.H., Brook, B.W., 2002. Nest site selection of the house crow (Corvus splendens), an urban invasive bird species in Singapore and implications for its management. Lands. Urb, Plan. 59, 217-226.

Sonerud, G.A., Hansen, H., Smedshaug, C.A., 2002. Individual roosting strategies in a flock-living bird: movement and social cohesion of hooded crows (Corvus corone cornix) from pre-roost gathering to roost sites. Behav. Ecol. Sociobiol. 51, 309-318.

Stewart, P.J., 1997. Some aspects of the ecology of an urban corvid: the Australian raven (Corvus coronoides) in metropolitan Perth. Unpublished BSc (Honours) Thesis, Edith Cowan University, Perth.

Stouffer, P.C., Caccamise, D.F. 1991. Roosting and diurnal movements of radio-tagged American crows. Wilson Bull. 103, 387-400.

Swingland, I.R., 1976. The influence of light intensity on the roosting times of the rook (Corvus frugilegus). Anim. Behav. 24, 154-158.

Thorpe, W.H., 1963. Learning and Instinct in Animals. Methuen, London.

Veerman, P., 2002. Canberra Birds: A report on the First 18 Years of the Garden Bird Survey. Philip Veerman, Canberra.

Ward, P., Zahavi, A., 1973. The importance of certain assemblages of birds as 'information centres' for food finding. Ibis 117, 517-534. 
1 Wittenberger, J.F., Hunt, G.L., 1985. The adaptive significance of coloniality in birds In: (Eds.). $2 \quad$ King, D.S., King, J.R., Avian Biology Vol. 8 Academic Press, London, pp 1-78.

3 Woodall, P.F., in press. Population changes of the Pied Currawong and Torresian crow in south-east $4 \quad$ Queensland over twenty years. Sunbird

5 Wright, J., Stone, R. E., Brown, N. 2003. Communal roosts as structured information centres in the 6 raven, Corvus corax. J. Anim. Ecol. 72, 1003-1014.

7 Zar, J.H., 1984. Biostatistical Analysis. Prentice Hall, New Jersey. 